\title{
What Do We Know About Fish Allergy at the End of the Decade?
}

\author{
Kourani E1, Corazza F², Michel $\mathrm{O}^{3}$, Doyen $\mathrm{V}^{3,4}$ \\ 'Pediatric department, Rafic Hariri University Hospital, Beirut, Lebanon \\ ${ }^{2}$ Laboratory of immunology (LHUB-ULB) and Laboratory of Translational Research, Brugmann University Hospital, Université Libre de Bruxelles \\ (ULB), Brussels, Belgium \\ ${ }^{3}$ Immuno-Allergology Clinic, Brugmann University Hospital, Université Libre de Bruxelles (ULB), Brussels, Belgium \\ ${ }^{4}$ Immuno-Allergology Clinic and Laboratory of Translational Research, Brugmann University Hospital, Université Libre de Bruxelles (ULB), \\ Brussels, Belgium
}

J Investig Allergol Clin Immunol 2019; Vol. 29(6): 414-421

doi: 10.18176/jiaci.0381

\begin{abstract}
Fish allergy is one of the most common food allergies. It is usually considered to be IgE-mediated and correlates well with diagnostic tests such as prick tests and/or determination of specific lgE. Avoidance is the recommended treatment and is generally extended to all fish species. However, new clinical presentations have been described. These include non-lgE-mediated disease, monosensitization, and new syndromes that are sometimes associated, surprisingly, with cross-reactivity. Advances in molecular allergy have provided insights into new allergens and have increased our understanding of cross-reactivity. This paper focuses on recent publications providing information for clinicians involved in the management of fish allergy.
\end{abstract}

Key words: Food allergy. Fish. Clinical aspects. Allergens. Parvalbumin. Pseudoallergy. Cross-reactivity.

\section{Resumen}

La alergia al pescado es una de las alergias alimentarias más frecuentes. Constituye habitualmente una alergia IgE mediada que se identifica correctamente mediante las pruebas cutáneas y/o la lgE específica in vitro. El tratamiento recomendado es la evitación de la ingesta habitualmente de todo tipo de pescados. Sin embargo, hay otras formas de presentación como la alergia no-lgE mediada, monosensibilizaciones y nuevos síndromes asociados a otros tipos de reactividad cruzada. Los avances en el diagnóstico molecular han descrito nuevos alérgenos y aumentado nuestro conocimiento sobre la reactividad cruzada. Este artículo analiza las publicaciones recientes que proporcionan nueva información para el tratamiento de la alergia a pescados.

Palabras clave: Alergia alimentaria. Pescado. Aspectos clínicos. Alérgenos. Parvalbúmina. Pseudoalergia. Reactividad cruzada. 


\section{Introduction}

Fish consumption has grown in recent years owing to nutritional content, and this increase has been associated with an increased frequency of fish allergy. The prevalence of fish allergy is variable and depends on local availability and consumption patterns. Furthermore, prevalence is difficult to estimate because of confusion with pseudoallergic reactions and reactions to shellfish. However, prevalence is generally considered to be lower than $1 \%$. Fish allergy is essentially IgE-mediated, although some non-IgE-mediated reactions have been described, especially in pediatric patients. Fish allergens can be transmitted by ingestion, by inhalation, and by skin contact, and the clinical manifestations can be mild, moderate, and severe. Cross-reactivity between various fish species is frequent, but patients who are allergic to one species (monoallergic) can tolerate exposure to other types without adverse reactions. Some surprising cross-reactions have been described between fish and other foods. This article discusses the most recent findings on fish allergy.

\section{Epidemiology}

Fish allergy is one of the 8 main food allergies and can affect both children and adults [1,2]. Labelling in industrialized countries requires mandatory declaration of fish content in food regardless of its quantity or proportion in which it is part of the final product. The prevalence of fish allergy has not been confirmed. However, it is thought to affect $<1 \%$ of the general population, with a range of $0 \%$ to $8 \%$ depending on the study population's dietary habits, the diagnostic criteria used, the mode of exposure, and the age of the population. It is more often seen in countries with higher fish consumption, such as Australia, Asia, and parts of Europe (Spain, Portugal, and Scandinavian countries) [2,3]. A 2016 review of 7333 articles by Moonesinghe et al [3], of which 61 studies met the inclusion criteria and were included, reported that the prevalence of fish allergy varies from $0 \%$ to $7 \%$, depending on the diagnostic method used, ie, self-questionnaire, prick test, IgE-based test, clinical history, and sensitization. When food challenge tests were used, the prevalence was only $0.3 \%$. In Norway, $3 \%$ of food allergies at the age of 2 years $(n=3623)$ are attributed to fish. In the USA, the prevalence of allergy to seafood was 5.9\% in 14948 study participants; $0.4 \%$ were allergic to fish, with most of these (67\%) being allergic to multiple fish species [5]. In a recent study of 4400 adults in the USA, the population-based prevalence of fish allergy in response to a phone survey was approximately $0.7 \%$ [5]. In Asia, prevalence was higher in the Philippines (2.29\%) and lower in Singapore (0.26\%) and Thailand $(0.29 \%)$ [4].

The prevalence of occupational asthma due to fish allergen exposure is estimated to account for $2 \%$ to $8 \%$ of cases of occupational asthma among exposed individuals $[1,5,6]$ and occurs mainly in countries where the fishing industry is important.

\section{Biological Classification}

Fish species are divided into 2 main groups: cartilaginous fish (Chondrichthyes: sharks and rays) and bony fish and Osteichthyes, which include 2 classes, Sacropterygii (lobe- finned fish: lungfish, coelacanths) and Actinopterygii (rayfinned fish: teleosts) $[4,7,8]$. Of the 30000 known species of fish, most are teleosts. A limited number of species are consumed frequently; these include Salmoniformes (salmon and trout), Gadiformes (cod and hake), Perciformes (mackerel and tuna), Clupeiformes (herring and sardine), Cypriniformes (carp and goldfish), Siluriformes (catfish), and Pleuronectiformes (sole, flounder, turbot, and halibut) $[1,5,9,10]$.

\section{Clinical Aspects of Fish Allergy}

Fish allergy is generally IgE-mediated, and affected patients present with immediate clinical signs, which are usually severe. The classic clinical signs include oral allergy syndrome, cutaneous symptoms (diffuse urticaria, angioedema), gastrointestinal manifestations (abdominal pain, diarrhea, and sudden-onset vomiting), respiratory symptoms (rhinitis, asthma), and, in the most severe cases, anaphylactic shock. Respiratory symptoms can occur due to inhalation of vapor while cooking fish [6]. Non-IgE-mediated reactions have mainly been reported in pediatric cases as food protein-induced enterocolitis syndrome (FPIES). The clinical presentation is different from IgE-mediated symptoms. Acute FPIES manifests within 1-4 hours after ingestion with repetitive emesis, pallor, and lethargy progressing to dehydration and, in some cases, hypovolemic shock. Chronic FPIES manifests with intermittent emesis, watery diarrhea, and poor growth progressing to dehydration. Diagnosis of FPIES relies on recognition of a pattern of clinical symptoms [11-13]. Fish is one the most frequent triggers of FPIES in Mediterranean countries [14]. A recent study in Spain by Vazquez-Otiz et al [11] showed that of 81 children who presented with FPIES, fish was the main trigger in $54.3 \%$ of cases. In another European series, FPIES due to fish was also common but only represented $12 \%-15 \%$ of FPIES cases [15-17]. Notably, these results differed from those found in other countries, particularly in the USA, where FPIES is frequently due to multiple foods [11]. FPIES induced by fish is characterized by particularities not found in other foods, ie, it begins later (except those caused by shellfish) and has a later resolution, at least than those produced by milk. FPIES has also been described for fish in adults and adolescents, where it is the second cause after shellfish $[18,19]$.

Occupational allergy due to exposure to fish allergens can lead to upper and lower respiratory symptoms (rhinitis, asthma), conjunctivitis, contact dermatitis, and urticaria. Anaphylaxis due to cutaneous contact has also been reported $[6,20]$. Few clinical studies have investigated the minimal eliciting doses for fish allergy. However, very low amounts of fish (in the milligram range) seem to be sufficient to trigger allergic symptoms in sensitized patients, and in the Europrevall study, the ED10 was established at $27 \mathrm{mg}[21,22]$. This could explain the allergic reactions to traces of protein in fish oils in specific patients.

Little is known about the natural history of fish allergy. For IgE-mediated allergies, sensitization generally starts during childhood and often persists until adulthood [23,24], although some patients develop clinical tolerance [20]. Published studies indicate that the outcome of FPIES is variable. In a Spanish cohort, $75 \%$ of children with FPIES 
triggered by fish acquired tolerance by 5 years of age [11], while other studies in Europe reported tolerance in 19\%-36\% of cases studied [15-17].

\section{Allergens}

The identification and accurate characterization of fish allergens from various species and regions allow more precise diagnoses and facilitate the prevention of allergic reactions [26]. However, at the molecular level, fewer than $0.5 \%$ of species have been analyzed. The analyses have mainly included fish that are commonly consumed in Europe, such as carp, salmon, trout, tuna, and cod $[5,10]$.

\section{Parvalbumin}

Parvalbumin proteins are the major fish allergen. These small muscle proteins (10- to $12-\mathrm{kDa}$ ) belong to the family of calcium-binding proteins and are resistant to enzymatic digestion and to heat [4]. The first fish allergen, parvalbumin, was identified from Baltic cod (Gad c 1 or allergen M). Since then, parvalbumin has been identified as an allergen in other species, including salmon (Sal s 1), mackerel (Sco a 1, Sco s 1, and Sco j 1), carp (Cyp c 1), and several species of tropical fish $[4,23]$.

The parvalbumin protein is globular in shape and contains 6 helices (termed helices A-F). Parvalbumin is a member of the EF-hand calcium-binding protein family, which are characterized by the presence of a helix, a loop, and a second helix, with both helices arranged like the spread thumb and index finger of a human hand $[1,4]$. Calcium binds to these helices via ionic bonds, resulting in conformational stability. Two parvalbumin isoforms have been identified, $\alpha$ and $\beta$. $\alpha$-Parvalbumin is found mainly in cartilaginous fishes and does not seem to be allergenic. The clinical cross-reactivity between $\alpha$ - and $\beta$-parvalbumin is very low in both fish classes (bony and cartilaginous), although this phenomenon is not fully understood. Most of the sequenced fish parvalbumin proteins are $\beta$ isoforms, which are found in bony fish $[1,4]$. Teleost fish have 2 types of muscle, white muscle (also called light muscle), which is used for short bursts of swimming, and dark muscle (also called red muscle), which is located directly under the skin and is used for continuous swimming. White fast-contracting muscle fibers have the highest concentration of parvalbumin (eg, flounder and cod), while red slow-contracting muscle fibers (eg, tuna and skipjack) contain lower levels. Since the proportion of white and red muscle varies between species, the parvalbumin content also varies [1,27]. Large migratory fish, such as those in the Xiphiidae family (eg, swordfish), have lower parvalbumin content than small sedentary fish (eg, cod, carp, redfish, and herring) [28,29]. For example, swordfish have less than $1 \mathrm{mg}$ of parvalbumin per gram of fresh fillet, similar to the concentration found in tuna [29] and other fish species, such as cod (Gadus morhua) and carp (Cyprinus carpio), which have more than $2.5 \mathrm{mg}$ of parvalbumin per gram [29]. Consequently, patients who are allergic to the parvalbumin in fish can tolerate certain species of bony fish with low parvalbumin concentrations, such as
Table. Sequenced Fish Allergens

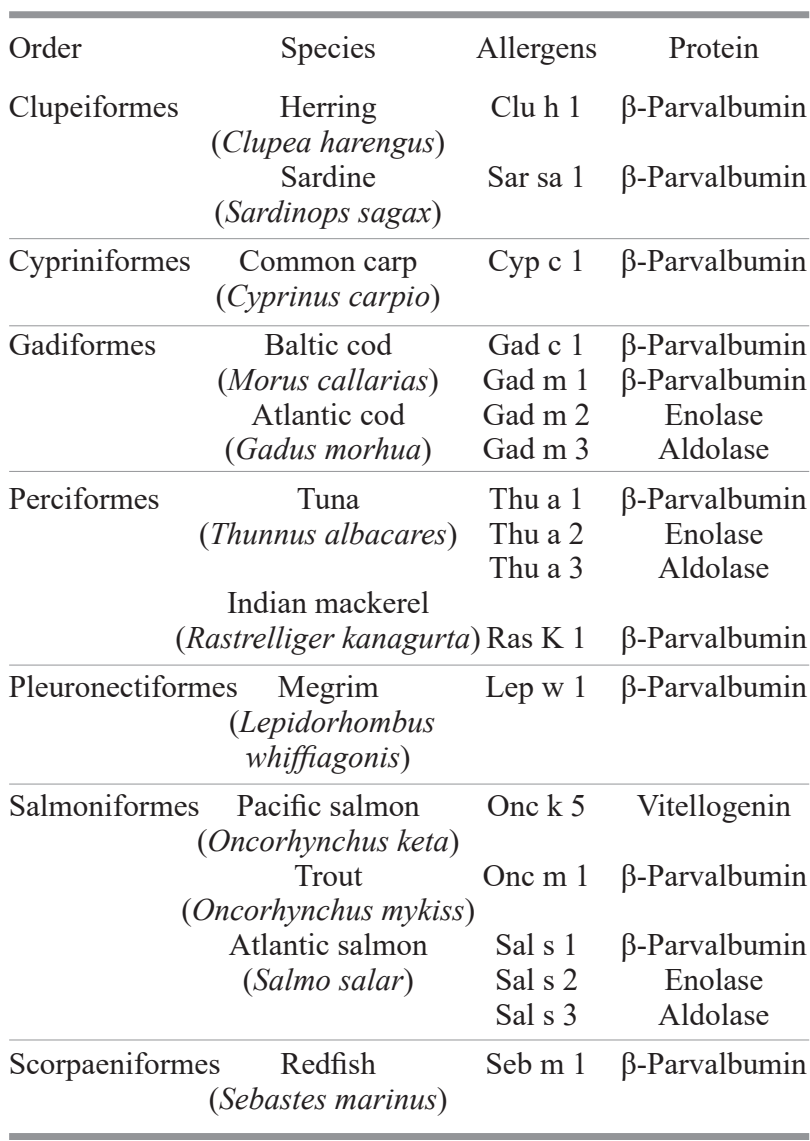

tuna and swordfish $[28,29]$. Additionally, the concentration of parvalbumin varies not only between species but also between parts of the fish, ie, it is higher in dorsal regions than in ventral regions and in rostral regions than in caudal regions [30].

Between $70 \%$ and $95 \%$ of patients who are allergic to fish have specific IgE against parvalbumin; the percentage varies depending on the type of fish used in the test and the population studied. Parvalbumin proteins from various fish species have a high level of sequence identity $(>70 \%)$ and show structural similarity, thus explaining IgE-dependent cross-reactivity with parvalbumin. It is important to note that these allergens contain other epitopes in more variable regions of the parvalbumin protein. Such epitopes represent specific antigenic determinants for specific species, and the IgE reactivity to these epitopes correlates with clinical monosensitization to a single species of fish $[1,4,7,9]$. An example can be seen in the exclusive allergy to salmonids resulting from monosensitization to its parvalbumin [31].

Interestingly, $\beta$-parvalbumin proteins from bony fish have a relatively high level of sequence identity with the $\alpha$-parvalbumin in amphibian muscle (63\% to $76 \%$ ), reptiles ( $56 \%$ to $69 \%$ ), and birds (54\% to $71 \%$ ) [4]. This may explain the clinical cross-reactivity between these species. The Table shows allergens that have been sequenced from various fish species $[4,10]$. 


\section{Other Allergens}

Other fish allergens have also been described. Both enolases and aldolases are clinically relevant in fish allergy, although the allergenicity of these proteins is less well established than the allergenicity of parvalbumin proteins $[1,10]$. Enolase $(50 \mathrm{kDa})$ and aldolase $(40 \mathrm{kDa})$ are enzymes involved in glucose metabolism. IgE reactivity against enolases and aldolases from tuna, salmon, and cod is found in patients who are sensitized and patients who are not sensitized to parvalbumin. These 2 enzymes are less stable than parvalbumin. Interspecies cross-reactivity for enolase and aldolase is limited and clearly lower than that between parvalbumins. In 2013, a study by Kuehn et al [24] estimated the prevalence of fish allergy due to enolase and aldolase to be $63 \%$ for enolase and $50 \%$ for aldolase. A recent case report of an 8-year-old patient with anaphylaxis due to swordfish revealed 4 proteins to be allergens, namely, pyruvate kinase, enolase, aldolase, and triosephosphate isomerase. This was the first report to describe these allergens in swordfish; notably, parvalbumin was not involved in the reaction [29].

Collagen was identified as a fish allergen in the early 2000 s. Collagen is a rod-shaped protein of about $330 \mathrm{kDa}$ that is present mainly in skin. A Japanese study performed in 2016 $(n=36)$ showed that $50 \%$ of patients who were allergic to fish had IgE reactivity to mackerel collagen [32]. Collagen from cartilaginous fish has lower allergenicity than collagen from bony fish [33]. Gelatin (collagen type I) is often used in the food industry and in pharmaceuticals to replace mammalian gelatin. The allergenicity of gelatin differs from that of collagen because of the destruction of some epitopes by the hydrolysis process. Fish collagen and gelatin found, respectively, in dietary supplements and marshmallows have been involved in allergic reactions $[35,36]$. Gelatin poses an allergenic risk due to potential contamination by parvalbumin. Indeed, traces of parvalbumin have been detected in isinglass, a type of gelatin that is used in the clarification of wine and that has, until now, been considered nonallergenic [37].

Tropomyosins are $\alpha$-helical proteins belonging to the family of actin-binding proteins. There are numerous isoforms in molds and in both muscle and nonmuscle cells of animals [38]. Tropomyosin is considered an invertebrate panallergen, and the tropomyosin found in vertebrates was not classically considered allergenic. Nevertheless, its allergenicity was first described in 2013 in tilapia from Mozambique (Oreochromis mossambicus) [39]. Subsequently, another group that used immunoblotting reported IgE-mediated immunoreactivity to tropomyosin from cod, yellow tuna, and swordfish in 10 of a cohort of 19 patients who presented with recurrent type I hypersensitivity following fish ingestion. It is particularly interesting to note that these patients had negative prick test results for commercial fish extracts [40]. The homology between invertebrate tropomyosin and fish tropomyosin is only $57 \%$, which, theoretically, is not sufficient to lead to clinical cross-reactivity [39]. However, Peixoto et al [41] described a child suspected of clinical cross-reactivity between fish and shrimp tropomyosin.

Vitellogenin is a protein found in fish eggs. It is resistant to enzymatic digestion, suggesting that the relevant allergens are subfragments of vitellogenin, such as lipovitellin and $\beta^{\prime}$-component $\left(\beta^{\prime}-c\right)$. Clinical reactivity to vitellogenin is variable and is often specific to certain types of caviar, although cross-reactivity has been reported with other fish eggs, especially between salmon eggs and herring eggs $[42,43]$. No cross-reactivity has been reported between chicken- and egg-equivalent proteins $[43,44]$.

Mention should be made of other potential fish allergens of unknown relevance such as aldehyde phosphate dehydrogenase, triosephosphate isomerase, glyceraldehyde-3-phosphatide dehydrogenase, and creatine kinase $[45,46]$.

\section{Cross-reactivity}

Clinical cross-reactivity between fish species is frequent, thus explaining why patients with fish allergy are often advised to avoid all species of fish and all fish-derived products [9]. However, numerous patients who are allergic to one fish species seem to tolerate other species. This difference in reactivity can be explained by the phylogenetic dispersion of species and by the different allergen contents [23]. For example, a patient who is allergic to the parvalbumin in fish may be able to tolerate certain species of fish that have low parvalbumin content, such as tuna and swordfish $[28,29,47]$. To date, monosensitivity has been described for sole, swordfish, pangasius/tilapia, tuna/ marlin, cod, and, more recently, salmon [21,48,49].

The weak clinical cross-reactivity between $\alpha$ - and $\beta$-parvalbumin in the 2 classes of fish (cartilaginous and bony) was not understood until recently $[1,4]$. A study by Kalic et al [50] of 17 patients with fish allergy showed that the specific IgE level and basophil activation were significantly lower for $\alpha$-parvalbumin from shark and ray than for $\beta$-parvalbumin from bony fishes. In some patients, the absence of clinical reactivity to ray was confirmed by oral challenge test. The researchers concluded that cartilaginous fish are well tolerated by patients allergic to bony fish, thereby helping the patients to avoid useless food restrictions. In the same sense, Calderon-Rodriguez et al [51] reported good tolerance to dogfish (a small shark frequently consumed in southern Spain) in patients allergic to bony fish. Moreover, the collagen of cartilaginous fish seems to be less allergenic than that of bony fish [33].

Cross-reactivity with other meat sources has also been described. For amphibians, cross-reactivity between fish and frog involves $\beta$-parvalbumin [52]. Recently, HarounDiaz et al [53] reported the first case of anaphylaxis due to cross-reactivity between fish and crocodile meat. Kuehn et al $[1,7,34,54]$ reported clinical cross-reactivity to poultry in a cohort of 36 patients with allergy to both fish and chicken meat, termed fish-chicken syndrome. Notably, both enolase (Gal d 9) and aldolase (Gal d 10) in chicken meat play major roles in this syndrome, as does parvalbumin ( Gal d 8). Fish-chicken syndrome seems to have a low prevalence. A retrospective study of the results of prick tests $(n=3232)$ that were conducted between 2012 and 2016 at Brugmann University Medical Center looked at the prevalence of the association between sensitization to chicken and allergy to fish and found an association in $14 \%$ of cases (unpublished data). The authors did not demonstrate immunological cross-reactivity, leading us to suspect that real cross-reactivity is even less prevalent. 
The sensitization profiles differed between the group of patients with allergy to fish and the group with allergy to chicken. The clinical presentation of patients with allergies to both is usually severe and seems to be evolutionary.

Cross-reactivity to fish and other seafood (shellfish, mollusks) has not been demonstrated. Although such crossreactivity has been suggested, the results of molecular analysis have not yet confirmed this hypothesis [7,21]. Tropomyosin would be the trigger allergen, and fish tropomyosin shows particular IgE specificity. However, serum samples from patients with shellfish allergy do not recognize any of the tropomyosin samples from fish tested in vitro. One proposed hypothesis is that vertebrate tropomyosin is digested into smaller fragments than invertebrate tropomyosin and that these smaller fragments no longer form the 3-dimensional $\operatorname{IgE}$ epitopes that are found in invertebrate tropomyosin [40].

\section{Effects of Processing and Digestion on Allergenicity}

Some industrial processes modify parvalbumin allergenicity. For example, the allergenicity of canned tuna is lower than the allergenicity of some fresh fish, which explains why some patients with fish allergy show tolerance to canned tuna [55]. Notably, there are no reported allergies to surimi, which contains the flesh of pasteurized fish. This is probably explained by the intensive processing the fish undergoes during manufacturing. Aldolases and enolase seem to be more sensitive to heat and food processing than parvalbumins [24].

Gastric acidity also affects allergenicity. A comparison of fish digested in $\mathrm{pH} 3$ environments with fish digested in more acidic $\mathrm{pH} 2$ environments (which is the normal gastric $\mathrm{pH}$ in humans) demonstrates that higher $\mathrm{pH}$ allows some allergenicity to be preserved. Consequently, antacid drugs can lead to incomplete allergen digestion $[4,5]$.

\section{Diagnosis}

Patient history and dietary survey remain important elements in the diagnosis of fish allergy. Prick tests based on commercial fish extracts or fresh fish plus allergen-specific IgE tests are routinely used to diagnose fish allergy. A prick test is frequently used as the first diagnostic test because it is rapid and inexpensive. Nevertheless, it has low specificity and a positive predictive value (PPV) of less than 50\% [5]. In addition, the efficacy of prick tests is limited by frequent cross-reactivity that is not clinically relevant $[1,4]$.

Allergen-specific IgE testing is generally a good indicator of sensitization to fish, although its ability to distinguish clinical reactivity from immunological cross-reactivity is limited. The cut-off depends on the population studied and has been reviewed by Garcia et al [56]. For example, for cod allergy, a specific IgE level of $20 \mathrm{kU} / \mathrm{L}$ has been shown to predict clinical reactivity $[4,56]$, while other authors have reported much lower cut-off points with a high PPV (ie, $0.35 \mathrm{kU} / \mathrm{L}$ with a PPV of $91 \%$ in adults, and $1.8 \mathrm{kU} / \mathrm{L}$ with a PPV of $71 \%$ in children and adolescents) [56]. More than 30 fish extracts and 2 molecular allergens of parvalbumin are available for use in specific IgE testing [1]. Notably, a negative result in specific IgE testing does not entirely exclude an allergic mechanism [57]. Gastrointestinal symptoms may not be accompanied by a positive prick test or specific IgE test result [58]. Clinical reactivity can be verified by oral challenge-ideally doubleblind - which is the gold standard for diagnosis [5].

\section{Differential Diagnosis}

Infestation by the helminth Anisakis simplex results in the contamination of fish flesh, which can cause severe allergic reactions in those who consume the fish. Symptoms can be digestive, cutaneous (urticaria, dermatitis), respiratory (asthma), and even anaphylactic. A new clinical concept of Anisakis allergy attributes this reaction not only to the presence of specific proteins derived from the parasite, but also to the presence of viable parasites [59]. This hypothesis was confirmed by an oral challenge test that used nonviable parasites, which was negative. Freezing at $-20^{\circ} \mathrm{C}$ for at least 24 hours is sufficient to kill the parasites [59]. Few studies have investigated the prevalence of Anisakis allergy. The current diagnostic approach is based on in vitro specific anti-Anisakis IgE testing and/or in vivo prick testing (when available) $[5,60]$. In a recent study in Italy, specific antiAnisakis IgE (CAP) was not detected in 9 cases among 20 children with a suggestive clinical history and positive prick test results [61].

Histamine poisoning, or scombroid syndrome, can cause pseudoallergy and stems from the high content of histamine in certain fish that have been badly preserved. Histamine is an endogenous amine that is produced by the conversion of histidine by histidine decarboxylase. The latter is found in bacteria that contaminate some preserved fish. The efficiency of histidine decarboxylase depends on temperature, $\mathrm{pH}$, and the sodium concentration. Ideally, fish should be kept at a temperature of $0^{\circ} \mathrm{C}$ or lower so that the bacteria cannot proliferate and so that the histidine decarboxylase cannot be activated [62]. Scombroid syndrome is a benign condition that begins 10 to 30 minutes after ingestion of fish and resolves spontaneously within 24 hours. The clinical presentation can be confused with that of fish allergy, although scombroid syndrome should be suspected in the presence of the following: abdominal pain, diarrhea, nausea, and vomiting; facial or generalized erythema; urticaria and/or edema; headache or dizziness; xerostomia and metallic or bitter taste; and palpitations. Respiratory symptoms and low blood pressure are rare [63].

\section{Treatment}

At present, the only treatment for fish allergy is strict avoidance of triggers and the use of epinephrine in patients with anaphylaxis. There are no published studies regarding specific oral immunotherapy, although the reduced allergenicity of canned tuna has enabled it to be used to induce tolerance. A 2011 study by Turner et al [55] of 167 patients with allergies to salmon and tuna showed that $20 \%$ of the patients can tolerate both species if the fish is canned. Prick testing with salmon and tuna revealed a reduced wheal size. 
Some researchers have used subcutaneous desensitization with fish extracts, although this treatment remains experimental. Therapies based on subcutaneous immunotherapy using hypoallergenic parvalbumin are currently being tested [64-66].

\section{Conclusion}

Allergic reactions to fish can be immediate and severe. Diagnosis is based on the clinical history, prick tests, specific IgE tests, and, if needed, oral challenge tests. The main fish allergens seem to be parvalbumin, enolase, aldolase, and collagen. Optimal management requires careful reflection to avoid unnecessary restriction, including consideration of the patient's allergic profile at the molecular level. However, the number of available fish allergens is very limited. Therapeutic hypoallergenic parvalbumin is being developed, although randomized controlled studies in large series are still needed.

\section{Funding}

The authors declare that no funding was received for the present study.

\section{Conflicts of Interest}

The authors declare that they have no conflicts of interest.

\section{References}

1. Kuehn A, Radauer C, Lopata A, Kleine-Tebbel J, Swoboda I. Extract-based and molecular diagnostics in fish allergy. Molecular Allergy Diagnostics. 2017;381-97.

2. Nwaru B.I, Hickstein L, Panesar S, Roberts G, Muraro A, Sheikh A. Prevalence of common food allergies in Europe: a systematic review and meta-analysis. Allergy. 2014;69:9921007.

3. Moonesinghe $H$, Mackenzie $H$, Venter $C$, Kilbrun S, Turner $P$, Weir K. Prevalence of fish and shellfish allergy: A systematic review. Ann Allergy Asthma Immunol. 2016;117:264-72.

4. Stephen JN, Sharp MF, Reuthers T, Taki A, Campbell DE, Lopata AL. Allergenicity of bony and cartilaginous fish - molecular and immunological properties. Clin Exp Allergy. 2017;47:30012.

5. Sharp M, Lopata A. Fish Allergy: In Review. Clinic Rev Allerg Immunol. 2014:46:258-71.

6. Lopata A, Jeebhay M. Airborne Seafood Allergens as a Cause of Occupational Allergy and Asthma. Curr Allergy Asthma Rep. 2013;13:288-97.

7. Kuehn A, Codreanu-Morel F, Lehners-Weber $C$, Doyen $V$, Gomez-André S-A, Bienvenu F. Cross-reactivity to fish and chicken meat - a new clinical syndrome. Allergy. 2016;71:1772-81

8. Tsabouri S, Triga M, Makris M, Kalogeromitros D, Church M, Priftis Kostas P. Fish and Shellfish Allergy in Children: Review of a persistent Food Allergy. Pediatric Allergy and Immunology. 2012;23:608-15.

9. Kuehn A, Morisset M, Hilger. Fish Allergens beyond betaParvalbumin. Revue Francaise d'aAllergologie. 2016;56:2601.
10. Paulsen L, Morisset M, Kuehn A. EAACI Molecular Allergology User's Guide.

11. Vazquez-Ortiz $M$, Machinena $A$, Dominguez $O$, Alvaro $M$, Calvo-Campoverde K, Giner M, et al. Food protein induced enterocolitis syndrome to fish and egg usually resolves by age 5 years in Spanish children. J Allergy Clin Immunol. 2017;5:512-5

12. Nowak-Węgrzyn A, Jarocka-Cyrta E, Moschione Castro A. Food Protein-Induced Enterocolitis Syndrome. J Investig Allergol Clin Immunol. 2017;27(1):1-18.

13. Vila Sexto L. Latest Insights on Food Protein-Induced Enterocolitis Syndrome: An Emerging Medical Condition. J Investig Allergol Clin Immunol. 2018;28:13-23.

14. Infante S, Marco-Martin G, Sanchez-Dominguez M, RodriguezFernandez A, Fuentes-Aparicio V, et al. Food protein-induced enterocolitis syndrome by fish: Not necessarily a restricted diet. Allergy. 2018;73:728-32.

15. Vila L, García V, Rial MJ, Novoa E, Cacharron T. Fish is a major trigger of solid food protein-induced enterocolitis syndrome in Spanish children. J Allergy Clin Immunol Pract. 2015;3:621-3.

16. Sopo SM, Monaco S, Badina L, Barni S, Longo G, Novembre $E$, et al. Food protein-induced enterocolitis syndrome caused by fish and/or shellfish in Italy. Pediatr Allergy Immunol. 2015;26:731-6.

17. González-Delgado P, Caparrós E, Moreno MV, Clemente F, Flores $E$, Velásquez $L$, et al. Clinical and immunological characteristics of a pediatric population with food proteininduced enterocolitis syndrome (FPIES) to fish. Pediatr Allergy Immunol. 2016;27:269-75.

18. Tan JA, Smith WB. Non-IgE-mediated gastrointestinal food hypersensitivity syndrome in adults. J Allergy Clin Immunol Pract. 2014;2:355-7.

19. Gonzalez-Delgado P, Caparrós E, Moreno MV, Cueva B, Fernández J. Food protein-induced enterocolitis-like syndrome in a population of adolescents and adults caused by seafood. J Allergy Clin Immunol Pract. 2019;2:670-72.

20. Jeebhay MF, Lopata AL. Occupational allergy in seafood processing workers. Adv Food Nutr Res. 2012;66:47-73.

21. Kuehn A, Swoboda I, Arumugam K, Hilger C, Hentges F. Fish allergens at a glance: variable allergenicity of parvalbumins, the major fish allergens. Front Immunol. 2014;5:179.

22. Ballmer-Weber BK, Fernandez-Rivas $M$, Beyer K, Defernez $M$, Sperrin M, Mackie AR, et al. How much is too much? Threshold dose distributions for 5 food allergens. J Allergy Clin Immunol. 2015:4:964-71.

23. Schulkes $K$, Klemans $R$, Knigge $L$, De Bruin-Weller $M$, Bruijnzeel-Koomen C, Marknell deWitt A. Specific IgE to fish extracts does not predict allergy to specific species within an adult fish allergic population. Clin Transl Allergy. 2014;4:27.

24. Kuehn A, Hilger C, Lehners-Weber C, Coderanu-Morel F, Morisset M, Metz-Favre $C$, et al. Identification of enolases and aldolases as important fish allergens in cod, salmon and tuna: component resolved diagnosis using parvalbumin and the new allergens. Clin Exp Allergy. 2013;43:811-22.

25. Thalayasingam M, Lee BW. Fish and Shellfish Allergy. Chem Immunol Allergy. 2015;101:152-61.

26. Rheuters T, Raith M, Sharp MF, Koeberl M, Stephen J, Nugraha $\mathrm{R}$, et al. Characterisation of Ras $\mathrm{k} 1$ a novel major allergen in Indian mackerel and identification of parvalbumin as the 
major fish allergen in 33 Asia-Pacific fish species. Clin Exp Allergy. 2018;48:452-63.

27. Kobayashi A, Tanaka H, Hamada Y, Ishizaki S, Nagashima Y, Shiomi K. Comparison of allergenicity and allergens between fish white and dark muscles. Allergy. 2006;61:357-63.

28. Kobayashi A, Kobayashi Y, Shiomi K. Fish allergy in patients with parvalbumin-specific Immunoglobulin E depends on parvalbumin content rather than molecular differences in the protein among fish species. Biosci Biotechnol Biochem. 2016;80:2018-21.

29. Valverde-Monge $M$, Pastor-Vargas $C$, Rodríguez del Rio $P$, Escudero C, Sánchez-García S, Mendez Brea P, etal.Anaphylaxis by exclusive allergy to swordfish and identification of a new fish allergen. Pediatr Allergy Immunol. 2018;29:563-5.

30. Kubota H, Kobayashi A, Kobayashi Y, Shiomi K, Hamada-Sato $\mathrm{N}$. Reduction in IgE reactivity of Pacific mackerel parvalbumin by heat treatment. Food Chem. 2016;206:78-84.

31. Kuehn A, Hutt-Kempf E, Hilger C, Hentges F. Clinical monosensitivity to salmonid fish linked to specific IgEepitopes on salmon and trout beta-parvalbumins. Allergy. 2011;66:299-301.

32. Kobayashi Y, Akiyama H, Huge J, Kubota H, Chikazawa S, Satoh T. Fish Collagen is an important panallergen in the Japanese population. Allergy. 2016;71:720-3.

33. Kobayashi Y, Kuriyama T, Nakagawara R, Aihara M, HamadaSato N. Allergy to fish collagen: Thermostability of collagen and IgE reactivity of patients' sera with extracts of 11 species of bony and cartilaginous fish. Allergol Int. 2016;65:450-8.

34. Hilger $C$, Van Hage $M$, Kuehn A. Diagnosis of allergy to mammals and fish: cross reactive vs specific markers. Curr Allergy Asthma Resp. 2017;17:64-76.

35. Kuehn A, Hilger C, Hentges F. Anaphylaxis provoked by ingestion of marshmallows containing fish gelatin. J Allergy Clin Immunol. 2009;123:708-9.

36. Fujimoto $W$, Fukuda $M$, Yokooji T, Yamamoto T, Tanaka A, Matsuo H. Anaphylaxis provoked by ingestion of hydrolysed fish collagen probably induced by epicutaneous sensitization. Allergol Int. 2016;65:474-6.

37. Walker S, Donet Camarena C, Freeman G. Alternatives to Isinglass for Beer Clarification. J Inst Brew. 2007;113:347-54

38. Geeves M, Hitchock-DeGregori S, Gunning P. A systematic nomenclature for mammalian tropomyosin isoforms. J Muscl Res Cell Mtil. 2015;36:147-53.

39. Liu R, Holck L, Yang E, Liu C, Xue W. Tropomyosin from tilapia (Oreochromis mossambicus) as an allergen. Clin Exp Allergy. 2013:43:365-77.

40. González-Fernández J, Alguacil-Guillén M, Cuéllar C, Daschner A. Possible Allergenic Role of Tropomyosin in Patients with Adverse Reactions after Fish Intake. Immunol Invest. 2018;47:416-29.

41. Peixoto $S$, Monteiro $T$, Carvalho $M$, Santos M, Matos $C$, Bartolomé B, et al. Vertebrate Tropomyosin as an Allergen. J Investig Allergol Clin Immunol. 2018;28:51-3.

42. González-De-Olano D, Rodríguez-Marco A, GonzálezMancebo E, Gandolfo-Cano M, Meléndez-Baltanás A, Bartolomé B. Allergy to red caviar. J Investig Allergol Clin Immunol. 2011:21:493-4.

43. Kondo $Y$, Kakami $M$, Koyama $H$, Yasuda $T$, Nikajima $Y$, Kawamura $\mathrm{M}$, et al. IgE cross-reactivity between fi shroe
(Salmon, Herring and Pollock) and chicken egg in patients anaphylactic to salmon roe. Allergol Int. 2005;54:317-23.

44. Perez-Gordo M, Sanchez-Garcia S, Cases B, Pastor C, Vivanco F, Cuesta-Herranz J. Identification of vitellogenin as an allergen in Beluga caviar allergy. Allergy. 2008;63:479-80.

45. Larco-Rojas X, González-Gutiérrez ML, Vázquez-Cortés S, Bartolomé B, Pastor-Vargas C, Fernández-Rivas M. Occupational Asthma and Urticaria in a Fishmonger Due to Creatine Kinase, a Cross-Reactive Fish Allergen. I Investig Allergol Clin Immunol. 2017;27:386-8.

46. Ruethers T, Taki AC, Johnston EB, Nugraha R, Le TTK, Kalic T, et al. Seafood allergy: A comprehensive review of fish and shellfish allergens. Mol Immunol. 2018 Aug;100:28-57.

47. Sørensen M, Kuehn A, Mills C, Costello C, Ollert $M_{\text {t }}$ Småbrekke L, et al. Cross-reactivity in Fish Allergy: A DoubleBlind Placebo-Controlled Food Challenge Trial. J Allergy Clin Immunol. 2017;140:1170-2.

48. Viñas M, Pineda F, Izquierdo-Domínguez A, Castillo M, Castillo MJ, Hernández N, et al. Allergy To Limanda aspera (Yellowfin Sole): Report of a Case of Food Allergy in a Child. J Investig Allergol Clin Immunol. 2018;28:137-8.

49. Ebo DG, Kuehn A, Bridts CH, Hilger C, Hentges F, Stevens WJ. Monosensitivity to pangasius and tilapia caused by allergens other than parvalbumin. J Investig Allergol Clin Immunol. 2010;20(1):84-8.

50. Kalic T, Morel-Codreanu F, Radauer C, Ruethers T, Taki AC, Swoboda I, et al. Patients Allergic to Fish Tolerate Ray Based on the Low Allergenicity of Its Parvalbumin. J Allergy Clin Immunol Pract. 2019;7:500-8.

51. Calderon-Rodriguez S, Pineda F, Perez R, Muñoz C. Tolerability to dogfish in children with fish allergy. Allergol Immunopathol (Madr). 2016 Mar-Apr;44:167-9.

52. Hilger $C$, Thill L, Grigioni F, Lehners $C$, Falagiani P, Ferrara A, et al. IgE antibodies of fish allergic patients cross-react with frog parvalbumin. Allergy. 2004;59:633-60.

53. Haroun-Díaz E, Blanca-López N, Vázquez de la Torre M, Javier Ruano, Somoza Álvarez ML, Labrador Horrillo M, et al. Severe anaphylaxis due to crocodile meat allergy exhibiting wide crossreactivity with fish allergens. J Allergy Clin Immunol Pract. 2018;6:669-70.

54. Kuehn A, Fisher J, Hilger C, Sparla C, Biedermann T, Hentges F. Correlation of clinical mono-sensitivity to cod with specific IgE to enolase and aldolase. Ann Allergy Asthma Immunol. 2014;113:670-1.

55. Turner $\mathrm{P}, \mathrm{Ng}$ I, Kemp A, Campell D. Sea-food allergy in children: a descriptive study. Ann Allergy Asthma Immunol. 2011;106:494-501.

56. García BE, Gamboa PM, Asturias JA, López-Hoyos M, Sanz ML, Caballero MT, et al. Guidelines on the clinical usefulness of determination of specific immunoglobulin $E$ to foods. J Investig Allergol Clin Immunol. 2009;19(6):423-32.

57. Barbarroja-Escudero J, Sánchez-González MJ, RodríguezRodríguez M, Antonlín-Amérigo D, Bartolomé B, Alvarez-Mon M. Bleak allergy: First case report. Allergol Int. 2016; 65;472-3

58. Chikazawa S, Hashimoto T, Kobayashi Y, Satoh T. Fish collagen allergy: a pitfall of the prick-to-prick test with raw fish. $\mathrm{Br} J$ Dermatol. 2015;173:1330-1.

59. Daschner A, Cuellar C, Rodero M. The Anisakis allergy debate: does an evolutionary approach help? Trends Parasitol. 2012;28;9-15. 
60. Nieuwenhuizen NE, Lopata AL. Allergic reactions to Anisakis found in fish. Curr Allergy Asthma Rep. 2014;14:455

61. Tripodi S, Pingitore G, Calvani M, Scala G, Rodriguez-Perez R, Sfika I, et al. Anisakis Sensitivity in Italian Children: A Prospective Study. J Investig Allergol Clin Immunol. 2017;27:142-3.

62. Feng C, Teuber S, Gershwin ME. Histamine (Scombroid) Fish Poisoning: a Comprehensive Review. Clin Rev Allergy Immunol. 2016;50:64-9.

63. Ridolo E, Martgnago I, Senna G, Ricci G. Scombroid syndrome: it seems to be fish allergy but... it isn't. Curr Opin Allergy Clin Immunol. 2016;16:516-21.

64. Zuidmeer-Jongejan L, Huber $H$, Swoboda I, Rigby N, Versteeg $\mathrm{SA}$, Jensen BM, et al. Development of a Hypoallergenic Recombinant Parvalbumin for First-in-Man Subcutaneous Immunotherapy of Fish Allergy. Int Arch Allergy Immunol. 2015;166:41-51.

65. Buonomo A, Nucera E, Schiavino D. Doctor, can I desensitize my food-allergic child using directly the allergenic molecules? Curr Opin Allergy Clin Immunol. 2016;16:278-83.
66. Doularidis N, Linhart B, Swoboda I, Gstotner A, Vassilopoulou E, Stolz F. In vivo allergenic activity of a hypoallergenic mutant of the major fish allergen Cyp c 1 evaluated by means of skin testing. J Allergy Clin Immunol. 2016;136:493-5.

- Manuscript received August 8, 2018; accepted for publication January 29, 2019.

\section{Virginie Doyen}

Immuno-Allergology Clinic Brugmann University Hospital Van Gehuchten Place, 4 1020 Brussels, Belgium E-mail: doyenv@yahoo.fr 